\title{
Pyrazole Studies
}

\author{
IX *. The Kinetics of Oxidation by Oxygen of 1,3,4-Substituted \\ Pyrazol-5-ones in the Presence of Hydroxyl or Alkoxyl Ions
}

\author{
STIG VEIBEL and S. C. LINHOLT
}

Department of Organic Chemistry, University of Technology, Copenhagen, Denmark

\begin{abstract}
1,3,4-Substituted pyrazol-5-ones are, in alcoholic solutions containing equivalent or excess amount of sodium hydroxide, oxidised by oxygen, one half molecule of oxygen being consumed per mole of pyrazolone. The order of the reaction is dependent on the solvent and on the substituents present. When the concentration of oxygen is kept constant a zero order scheme is usually followed but in some cases a first order scheme, in others more complicated schemes are followed.

The yield of 4-hydroxysubstituted pyrazol-5-one is usually almost quantitative, independent of the order of the reaction.
\end{abstract}

Tn a previous paper (Veibel and Linholt ${ }^{1}$ ) was shown that 4-alkylsubstituIted pyrazol-5-ones dissolved in methanol are oxidised to 4-alkyl-4-hydroxysubstituted pyrazolones by oxygen in the presence of triethylamine (which is at the same time oxidised to triethylamine oxide), one mole of oxygen being consumed per mole of pyrazolone.

We now found that this oxidation also takes place when an inorganic base such as the hydroxide ion or an organic base such as the ethanolate ion is present, but as these bases are not oxidised themselves the consumption of oxygen is only one half mole per mole of pyrazolone.

The oxidation of pyrazolones substituted at $\mathrm{N}_{1}$ in the presence of triethylamine follows a first order scheme ${ }^{1}$. In the presence of the above named bases in alcoholic solution, more or less water being present, the oxidation usually follows a zero order scheme (care being taken that the concentration of oxygen is kept constant during the reaction), the velocity of consumption of oxygen being independent of the concentration of pyrazolone. The velocity is, however, strongly dependent on the alcohol used as solvent (investigated were methanol and tert. butanol) and the amount of water present.

* VIII: Acta Chem. Scand. 8 (1954) 1383.

Acta Chem. Scand. 9 (1955) No. 6 
Table 1, No. II, shows that for a particular pyrazolone the type of the reaotion may shift from first order to zero order when tert. butanol is used instead of methanol or when the water content of the solvent (methanol) is reduced from some $10 \%$ to some $2 \%$, but Table 1, No. VIII, shows that the inverse shift of reaction order is possible too.

The yield of the hydroxy compound isolated is practically independent of the order of reaction and the velocity of oxidation.

It seems inevitable to admit that the mechanism of the reaction in the presence of hydroxyl or ethanolate ions is different from the mechanism followed in the presence of tertiary amines. For the latter reaction we assumed the scheme:

$$
\begin{aligned}
& \mathrm{PyRH}+\left(\mathrm{C}_{2} \mathrm{H}_{5}\right)_{8} \mathrm{~N} \rightleftharpoons \mathrm{PyR}^{-}+\left(\mathrm{C}_{2} \mathrm{H}_{5}\right)_{2} \stackrel{+}{\mathrm{N}} \mathrm{H} \\
& \mathrm{PyR}^{-}+\mathrm{O}_{2} \longrightarrow \text { PyROO- }^{-} \\
& 2 \mathrm{PyROO}^{-}+2\left(\mathrm{C}_{2} \mathrm{H}_{8}\right)_{3} \stackrel{+}{\mathrm{N} H} \longrightarrow \underset{\uparrow}{\stackrel{\text { PyROH }}{\stackrel{\mathrm{N}}{\mathrm{N}}\left(\mathrm{C}_{2} \mathrm{H}_{8}\right)_{3}}} \\
& \underset{\substack{\uparrow \\
\stackrel{\uparrow}{N}\left(\mathrm{C}_{2} \mathrm{H}_{8}\right)_{2}}}{\longrightarrow} 2 \text { PyROH }+\left(\mathrm{C}_{2} \mathrm{H}_{8}\right)_{2} \mathrm{~N}\left(\mathrm{OH}_{2}\right)
\end{aligned}
$$

PyRH meaning a 4-monoalkyl- or arylsubstituted pyrazol-5-one, at the same time alkyl- or arylsubstituted at $\mathrm{C}_{3}$ and at $\mathrm{N}_{1}$.

In the presence of sodium hydroxide the reaction presumably proceeds through the same initial stages (a) and (b) as above. But as water cannot be oxidised as could the triethylammonium ion another sequence of reactions starts. The possibility first considered was:

$$
\text { PyROO- }^{\rightarrow} \text { PyRO- }^{-1 / 2} \mathrm{O}_{2}
$$

\begin{tabular}{|c|c|c|}
\hline 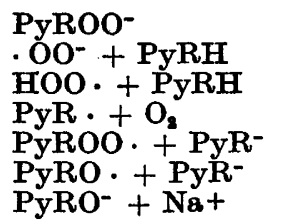 & $\begin{array}{l}\vec{\longrightarrow} \\
\vec{\longrightarrow} \\
\vec{\longrightarrow}\end{array}$ & 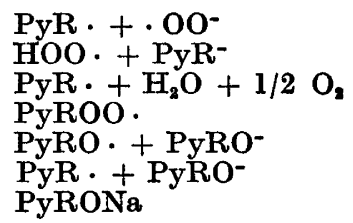 \\
\hline
\end{tabular}

but presumably a first order scheme would result for the overall reaction. A radical mechanism being indicated by the zero order scheme followed, we then considered the sequence:

The chain is fully established in the reactions $\left(f_{1}\right) \rightarrow\left(g_{1}\right) \rightarrow\left(h_{1}\right)$. A chain breaking reaction would be $\mathrm{PyR} \cdot+\mathrm{PyR} \cdot \rightarrow \mathrm{RPy}-\mathrm{PyR}$ but we so far did not observe the formation of a bis-pyrazolone.

The initial reactions $(a) \rightarrow(b) \rightarrow\left(c_{1}\right) \rightarrow\left(d_{1}\right) \rightarrow\left(\theta_{1}\right)$ might explain the existence of an induction period. In a few instances we observed a short period of induction but usually the zero order reaction was established at once.

In many instances we observed a consumption of oxygen somewhat greater than one half mole per mole of pyrazolone, possibly due to the formation of 
$\mathrm{O}_{2}^{--}$or to a further oxidation of the pyrazolone or the hydroxypyrazolone. We never succeeded in establishing the presence of hydrogen peroxide during the reaction.

In some instances the reaction follows a first order scheme whereas in other instances (mainly such pyrazolones where the oxidation proceeds slowly) a more complex reaction seems to take place, following neither a zero order, nor a first order nor a second order scheme. We have so far not succeeded in establishing the conditions determining the kinetics of the reaction. More accurate kinetic investigations are in preparation, including experiments with variation of the oxygen pressure.

The first order scheme is represented by the sequence:

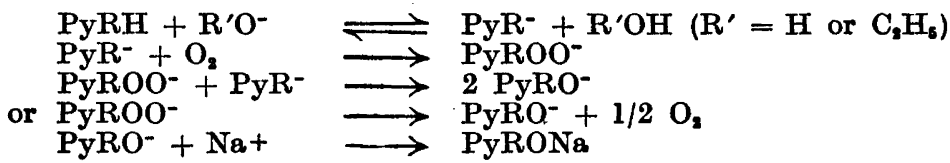

When (b) is slow as compared with the other reactions this reaction will determine the rate, $i . e$. at constant pressure of oxygen the consumption of oxygen will be proportional to the pressure of oxygen and the concentration of pyrazolone (or of pyrazolone ion):

$$
\frac{\mathrm{d} x}{\mathrm{~d} t_{i}}=k_{1} \cdot p_{\mathrm{o}_{1}} \cdot c_{\mathrm{py}}
$$

On the other hand $c_{\mathrm{py}}=k_{0} \cdot \frac{a-x}{a}$

where $a$ is the volume of oxygen necessary for complete reaction and $x$ the volume consumed at the time $t$. From this we get:

$$
\frac{\mathrm{d} x}{\mathrm{~d} t}=k_{1} \cdot p_{\mathrm{O}} \cdot k_{0} \cdot \frac{a-x}{a}=K_{0} \cdot \frac{a-x}{\mathrm{a}}
$$

i.e. a first order scheme.

When ( $\left.c^{\prime}\right)$ is followed instead of (c) the same expression holds good with a new value of the constant, but the (c) type of reaction is possibly more likely than the $\left(c^{\prime}\right)$ type when regard is payed to the reaction between pyrazolones and tert. butylhydroperoxide described previously ${ }^{2}$.

\section{EXPERIMENTAL PART *}

All pyrazolones investigated were prepared by current methods (for references see 1 and ${ }^{2}$ ). The 4-hydroxypyrazolones, too, have been recorded (Veibel and Linholt ${ }^{2,3}$ ) with the exception of the oxidation products of $\mathbf{X}$ and $\mathrm{XI}$.

1,3-Dimethyl-4-hydroxy-4-phenylpyrazol-5-one (X ox ). $1.9 \mathrm{~g}$ of 1,3-dimethyl-4-phenylpyrazol-5-one were dissolved in $20 \mathrm{ml}$ of methanol, $2 \mathrm{ml}$ of $5 \mathrm{~N}$ aqueous sodium hydroxide were added and the solution made up with methanol to $25 \mathrm{ml}$ in a $100 \mathrm{ml}$ flask. The air was expelled by oxygen and then the technique described previously ${ }^{1}$ was applied.

* All m. p.'s uncorrected. Microanalyses by Mr. P. Hansen, Department of Organic Chemistry, University of Copenhagen.

Acta Chem. Scand. 9 (1955) No. 6 


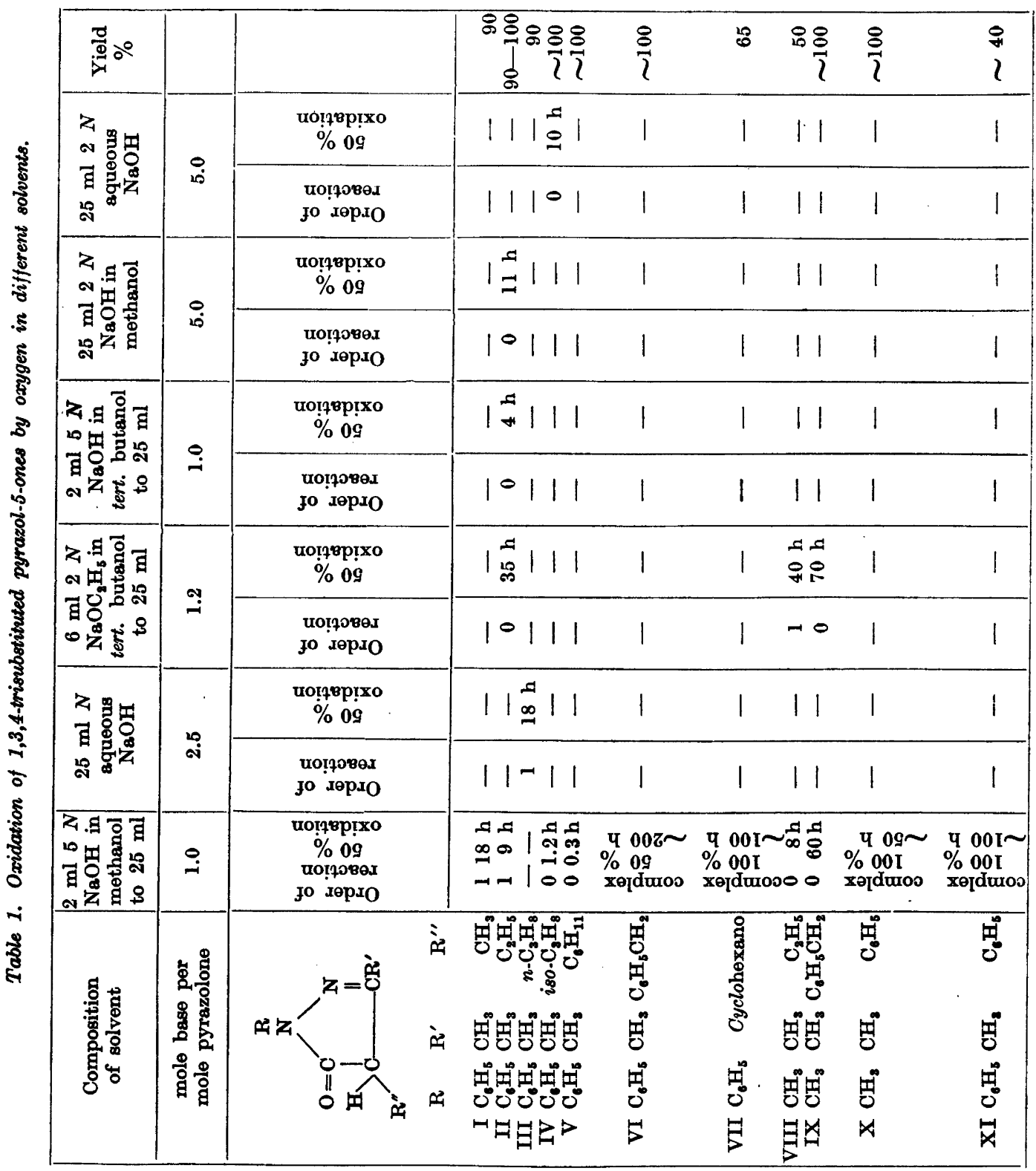




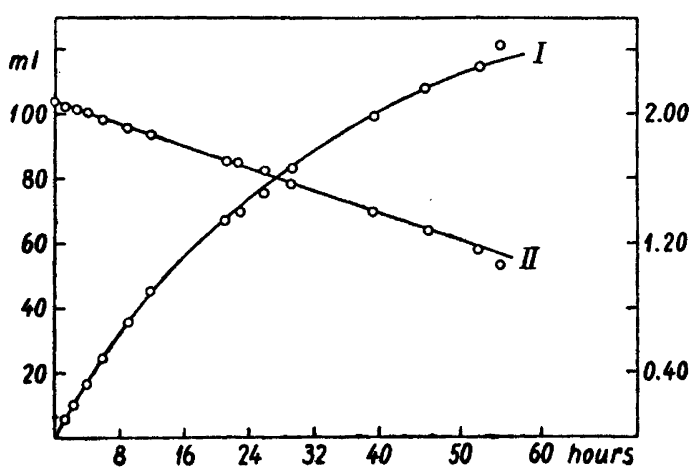

Fig. 1. 1-Phenyl-3,4-dimethylpyrazol-5-one.

I. Absorption of oxygen. (Ordinate left)

II. $\log (c-x) \mid x$

(Ordinate right)

The solution remained clear and colourless all during the oxidation. When no more oxygen was absorbed the flask was disconnected from the gas-burette, the sodium hydroxide was neutralised with hydrochloric acid and the solvents removed in vacuo (bath temperature $\sim 50^{\circ}$ ), leaving the hydroxypyrazolone in nearly quantitative yield, $\mathrm{m}$. $p$. $126^{\circ}$; recrystallised from aqueous ethanol (in order to remove sodium chloride) it was obtained as long needles with m. p. 126-127 . (Found: C 64.51; H 5.83; N 13.30. Calc. for $\mathrm{C}_{11} \mathrm{H}_{12} \mathrm{O}_{2} \mathrm{~N}_{2}$ (204.2): $\mathrm{C} 64.68 ; \mathrm{H}$ 5.93; $\mathrm{N}$ 13.72).

1,4-Diphenyl-4-hydroxy-3-methylpyrazol-5-one (XI ox). $12.5 \mathrm{~g}$ of 1,4-diphenyl-3. methylpyrazol-5-one were dissolved in $100 \mathrm{ml}$ of methanol, $10 \mathrm{ml}$ of $5 \mathrm{~N}$ aqueous sodium

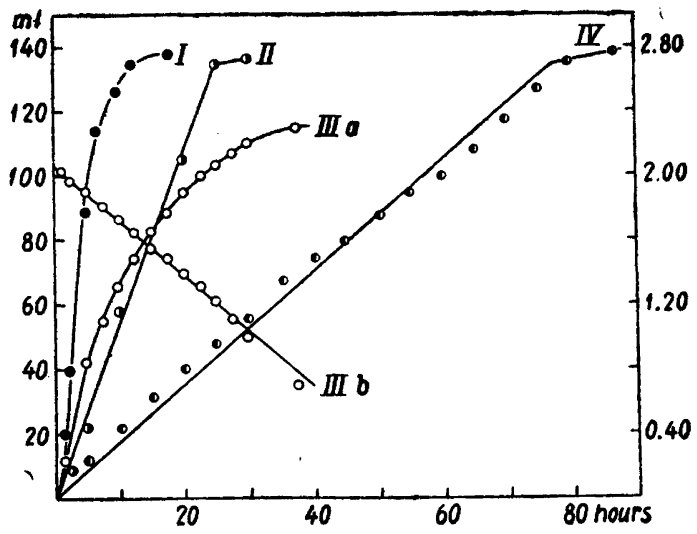

Fig. 2. 1-Phenyl-3-methyl-4-ethylpyrazol-5-one.

I. $\quad 0.01$ mole $+2 \mathrm{ml} 5 \mathrm{~N} \mathrm{NaOH}$ diluted to $25 \mathrm{ml}$ with tert. butanol.

II. 0.01 mole $+25 \mathrm{ml} 2 \mathrm{~N} \mathrm{NaOH}$ in methanol.

III a. 0.01 mole $+2 \mathrm{ml} 5 \mathrm{~N} \mathrm{NaOH}$ diluted with methanol to $25 \mathrm{ml}$. Absorption of oxygen (Ordinate left)

III b. As III a. $\log (c-x)(x$ (Ordinate right)

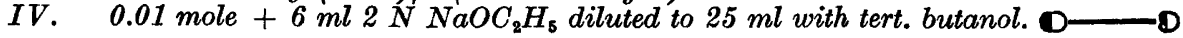

Acta Chem. Scand. 9 (1955) No. 6 


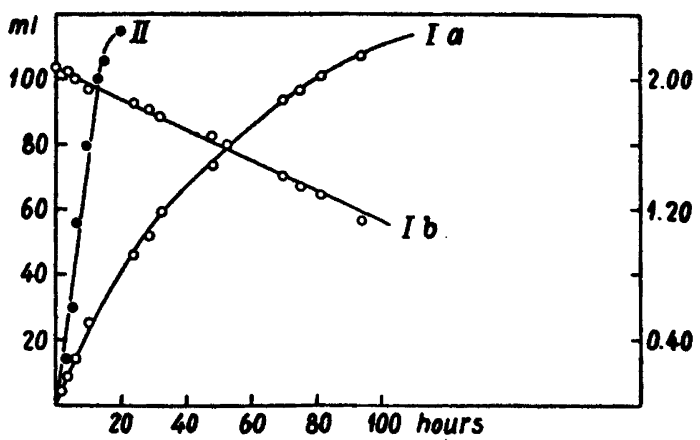

Fig. 3. 1,3-Dimethyl-4-ethylpyrazol-5-one.

I a. 0.01 mole $+6 \mathrm{ml} 2 \mathrm{~N} \mathrm{NaOC} \mathrm{CH}_{5}+14 \mathrm{ml}$ tert. butanol, Absorption of oxygen (Ordinate left)

I b. As $I$ a. $\log (c-x) / x$ (Ordinate right)

II. $\quad 0.01$ mole $+2 \mathrm{ml} 5 \mathrm{~N} \mathrm{NaOH}$ diluted to $25 \mathrm{ml}$ with methanol.

hydroxide were added and the solution made up with methanol to $125 \mathrm{ml}$ in a $500 \mathrm{ml}$ flask. The procedure indicated above was followed for the oxidation. When no more oxygen was absorbed an excess of hydrochloric acid was added to the solution which had turned brown during the oxidation, and the solvents were removed in vacuo (bath tem. perature $\sim 50^{\circ}$ ). A few ml of water were added to the solid residue to remove sodium chloride. The residue was isolated by suction and washed with water. Yield $6.5 \mathrm{~g}=50 \%$ of a coloured substance which was decolourised by treating its methanolic solution with absorption carbon; m. p. $135^{\circ}$ which on repeated recrystallisations from aqueous methanol was raised to $141-143^{\circ}$. (Found: $\mathrm{C} \mathrm{72.35} ; \mathrm{H} 5.36 ; \mathrm{N} 10.11$. Calc. for $\mathrm{C}_{18} \mathrm{H}_{14} \mathrm{O}_{2} \mathrm{~N}_{2}$ (266.3) : C 72.15; H 5.30; N 10.52).

When 1,4-diphenyl-3-methylpyrazol-5-one was oxidised with tert. butylhydroperoxide as indicated by Veibel and Linholt a hydroxy compound was obtained in good yield, showing m. p. $155-56^{\circ}$ (Found: C 72.35; H 5.36; $\mathrm{N} 10.40$. Calc. as above). A mixed m. p. of the two substances showed slight depression. Obviously the oxidation by oxygen is more complex than the oxidation with tert. butylhydroperoxide. Only about $60 \%$

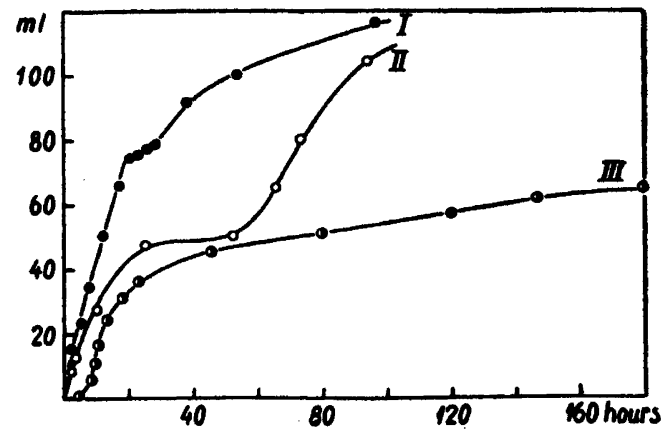

Fig. 4. I. 1-Phenyl-3-methyl-4-benzylpyrazol-5-one.

II. 1,3-Dimethyl-4-phenylpyrazol-5-one.

III. 1,4-Diphenyl-3-methylpyrazol-5-one.

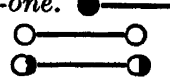

Acta Chem. Scand. 9 (1955) No. 6 
of the calculated volume of oxygen was consumed during 180 hours, no more oxygen being consumed during the next 80 hours. This pyrazolone is the only one investigated so far which does not consume at least one half mole of oxygen per mole of pyrazolone.

Oxidation of pyrazolones. Table 1 gives a summary of the results obtained.

F g. 1 (pyrazolone I) shows a typical example where a first order scheme is followed.

In Fig. 2 the results obtained with pyrazolone II are recorded. It is seen that only with a methanolic solution containing equivalent amounts of pyrazolone and sodium hydroxide and, in addition, $c a .10 \%$ of water a first order scheme is followed (curve III), the oxygen consumed not exceeding the calculated amount. When tert. butanol is used as solvent instead of methanol (curves I and IV) or when the methanolic solution contains only $1-2 \%$ of water, the ratio sodium hydroxide : pyrazolone being 5:1 (curve II), the reaction follows a zero order scheme and the consumption of oxygen exceeds the calculated volume by some $25 \%$. The velocity of the oxidation, too, is strongly dependent on the solvent used and the ratio base : pyrazolone. A more thorough investigation of the influence of these different factors is in preparation.

Fig. 3 shows that when pyrazolone VIII is oxidised a first order scheme is followed when the pyrazolone is dissolved in anhydrous tert. butanol, 1.2 moles of sodium ethanolate being present per mole of pyrazolone, whereas a zero order scheme is followed in methanol with 1 mole of sodium hydroxide, $10 \%$ of water being present, $i$. e. the inverse of that found for the pyrazolone II.

Finally are in Fig. 4 recorded the oxidations of some pyrazolones where no definite scheme is followed (VI, $X$ and XI). A closer investigation of the oxidation of these more complex cases is in preparation and no attempt to interpret the curves found here shall be ventured.

\section{REFERENCES}

1. Veibel, S. and Linholt, S. C. Acta Chem. Scand. 8 (1954) 1007.

2. Veibel. S. and Linholt, S. C. Acta Chem. Scand. 8 (1954) 1383.

3. Veibel, S., Eggersen, K. and Linholt, S. C. Acta Chem. Scand. 8 (1954) 768.

Received April 18, 1955. 